Check for updates

Cite this: RSC Adv., 2017, 7, 22492

Received 15th March 2017

Accepted 17th April 2017

DOI: $10.1039 / c 7 r a 03066 e$

rsc.li/rsc-advances

\section{Facile preparation of high-quality perovskites for efficient solar cells via a fast conversion of wet $\mathrm{Pbl}_{2}$ precursor films $\uparrow$}

\author{
Chongyang Sun, ${ }^{a}$ Yiping Guo, (D) *a Bijun Fang, ${ }^{\mathrm{b}}$ Lin Guan, ${ }^{a}$ Huanan Duan, ${ }^{a}$ \\ Yujie Chen, ${ }^{a}$ Hua Li ${ }^{a}$ and Hezhou Liu*a
}

\begin{abstract}
High-performance perovskite solar cells are strongly dependent on the quality of the perovskite layer. Here, a high crystallinity, sufficiently smooth and pinhole-free $\mathrm{CH}_{3} \mathrm{NH}_{3} \mathrm{Pbl}_{3}$ film with excellent photovoltaic properties has been successfully prepared by a facile and reproducible approach, in which the $\mathrm{CH}_{3} \mathrm{NH}_{3} \mathrm{l}$ (MAl) was deposited directly onto wet $\mathrm{Pbl}_{2}\left(\mathrm{w}-\mathrm{Pbl}_{2}\right)$ precursor films. It is found that the outstanding morphology and low crystallization of the $\mathrm{w}-\mathrm{Pbl}_{2}$ film significantly promotes the conversion of $\mathrm{Pbl}_{2}$ to $\mathrm{CH}_{3} \mathrm{NH}_{3} \mathrm{Pbl}_{3}$, improves the morphology and crystallinity of the perovskite, and leads to further reduction of the recombination of photogenerated carriers and increment of the lifetimes of charge carriers in the fabricated devices. Compared with the control devices fabricated using a conventional dry and compact $\mathrm{Pbl}_{2}$ film, perovskite solar cells fabricated by using this new method show much higher efficiency and reproducibility. The average power conversion efficiency of the fabricated solar cells is greatly improved from $9.76 \pm 0.46 \%$ to $15.22 \pm 0.17 \%$, which is an increase of nearly $56 \%$. Thus, we demonstrate an effective strategy to prepare high-quality perovskite films with excellent photovoltaic properties.
\end{abstract}

\section{Introduction}

Since the pioneering work using $\mathrm{CH}_{3} \mathrm{NH}_{3} \mathrm{PbX}_{3}(\mathrm{X}=\mathrm{I}$, or $\mathrm{Br}$ ) as a light absorber in a solar cell, ${ }^{1}$ inorganic-organic lead halide perovskite solar cells have become one of the most promising candidates in preparing low cost and high-efficiency solar cells. As a light-absorber, the perovskite materials have demonstrated excellent photovoltaic properties, i.e., large light absorption coefficient, long electron-hole diffusion lengths, high carrier mobility, and easily tunable band gap. ${ }^{2-6}$ This new type of costeffective solar cell has attracted intensive attention since the power conversion efficiency (PCE) skyrocketed from $3.8 \%$ in 2009 to a recent $22.1 \% .^{7-14}$ The high-performance of PSCs is strongly dependent on the perovskite film quality such as its phase, crystallinity, morphology, coverage and so on. Various methods, e.g., solution deposition (two-step sequential deposition $^{15,16}$ or one-step spin coating $\left.{ }^{17,18}\right)$, low-temperature vapourassisted solution deposition, ${ }^{19,20}$ and vacuum evaporation deposition, ${ }^{21,22}$ have been reported for the formation of high-

${ }^{a}$ State Key Laboratory of Metal Matrix Composites, School of Materials Science and Engineering, Shanghai Jiao Tong University, Dongchuan Road No. 800, Minhang District, Shanghai,200240, P. R. China. E-mail: ypguo@sjtu.edu.cn; hzhliu@sjtu. edu.cn

${ }^{b}$ Jiangsu Key Laboratory for Solar Cell Materials and Technology, School of Materials Science and Engineering, Changzhou University, China

$\dagger$ Electronic supplementary information (ESI) available: Cross-sectional SEM images, AFM topographies of perovskite films; $J-V$ curves of the best perovskite solar cell fabricated by w-PbI ${ }_{2}$ film. See DOI: $10.1039 / \mathrm{c} 7 \mathrm{ra03066e}$ quality perovskite layers. Among them, the two-step sequential deposition technique was demonstrated to be useful for preparing perovskite films for high-performance PSCs. In the standard sequential deposition process, the critical step is the reaction of $\mathrm{PbI}_{2}$ films with $\mathrm{CH}_{3} \mathrm{NH}_{3} \mathrm{I}$ (MAI), and the initially predeposited $\mathrm{PbI}_{2}$ precursor film undergoes an intercalation reaction with organic iodide in the isopropanol (IPA) solution to form $\mathrm{CH}_{3} \mathrm{NH}_{3} \mathrm{PbI}_{3}$ (or $\mathrm{MAPbI}_{3}$ ). However, the well-crystallized and compact $\mathrm{PbI}_{2}$ film and space-expansion-induced $\mathrm{MAPbI}_{3}$ surface layer would significantly inhibit the complete conversion of $\mathrm{PbI}_{2}$ to $\mathrm{MAPbI}_{3}$ within a short dipping time. ${ }^{23,24}$ Longer dipping time (from tens of minutes to several hours) could increase the conversion. However, dipping too long would result in the abnormal growth of perovskite crystals and/or the dissolution or peel-off of perovskite films, ${ }^{25-27}$ both of which are detrimental to the efficiency. To shorten the dipping time, increasing reaction temperature ${ }^{28}$ and IPA pre-wetting ${ }^{15}$ are commonly implemented. However, both of them accelerate the reaction between $\mathrm{PbI}_{2}$ and $\mathrm{CH}_{3} \mathrm{NH}_{3} \mathrm{I}$ as well as the abnormal growth of perovskites, undermining the reproducibility. ${ }^{28,29} \mathrm{It}$ is, therefore, important to develop a facile and reproducible fabrication method to accelerate the reaction without causing the abnormal growth of perovskite crystals for highly efficient solar cells.

To address the $\mathrm{PbI}_{2}$ residue issue for producing highperformance perovskite films, some strategies have been developed. ${ }^{8,30-35}$ Recently, we demonstrated that the incorporation of polymer $\mathrm{P}(\mathrm{VDF}-\mathrm{TrFE})$ into the $\mathrm{PbI}_{2}$ precursor film can 
achieve the complete conversion of $\mathrm{PbI}_{2}$ to $\mathrm{MAPbI}_{3}$ by retarding the crystallization of $\mathrm{PbI}_{2} \cdot{ }^{36}$ Gong et al. ${ }^{37}$ reported that the application of the mesoporous $\mathrm{PbI}_{2}$ scaffolds, employing the nucleation and growth of $\mathrm{PbI}_{2}$ crystallites in a wet film, can be rapidly converted into perovskite films without any $\mathrm{PbI}_{2}$ residue. Additionally, some researchers also introduced a strongly coordinative solvent of dimethyl sulfoxide (DMSO) into the dimethylformamide (DMF) precursor solution of $\mathrm{PbI}_{2}$ with an aim at forming the different $\mathrm{PbI}_{2}(\mathrm{DMSO})_{x}$ complexes and retarding the crystallization of $\mathrm{PbI}_{2}$, which facilitated the conversion of lead iodide to perovskites and the formation of high-quality perovskite films after high-temperature thermal annealing. ${ }^{13,38,39}$ Nevertheless, the existing techniques suffer from the complicated procedure for retarding the crystallization of $\mathrm{PbI}_{2}$, fabrication of the porous $\mathrm{PbI}_{2}$ films and non-energy saving.

In this work, we demonstrated a facile and reproducible way to prepare high quality perovskite films with excellent photovoltaic performance by using an annealing-free, wet $\mathrm{PbI}_{2}$ precursor film. There is a direct molecular substitution reaction of weakly coordinative solvent DMF with MAI in the wet $\mathrm{PbI}_{2}$ films to form $\mathrm{MAPbI}_{3}$ at low temperature. Using this strategy, it only takes tens of seconds to achieve complete conversion of $\mathrm{PbI}_{2}$ to $\mathrm{MAPbI}_{3}$. Through studying the perovskite formation over crystallization kinetics and film qualities, carrier lifetimes, defects etc., we reveal that the presence of solvent molecule (DMF), as ligands in wet $\mathrm{PbI}_{2}$ precursor films, is effective to accelerate the conversion of $\mathrm{PbI}_{2}$ precursors to $\mathrm{MAPbI}_{3}$ perovskite films. $\mathrm{PbI}_{2}$ with the weak coordinating ligand DMF can be quickly converted into high-quality perovskite films even at room temperature. The resultant perovskite film showed densely packed large grains and ultra-smooth surface, leading to a much reduced film defects and longer carrier lifetime. As a result, we obtained high-quality bilayer-structured perovskite films with around $200 \mathrm{~nm}$-thickness capping layer, resulting in the champion efficiency of above $15 \%$.

\section{Experimental}

\section{Materials and device fabrication}

Unless stated otherwise, all chemicals were purchased from SigmaAldrich and used as received. $\mathrm{TiO}_{2}$ paste, $2,2^{\prime}, 7,7^{\prime}$-tetrakis $[N, N$-di( $(4-$ methoxyphenyl)amino]-9,9'-spirobifluorene

(spiro-MeOTAD) $(\geq 99.0 \%), \quad$ Li-bis(trifluoromethanesulfonyl) imide (Li-TFSI) $(\geq 99.5 \%)$, and 4-tert-butylpyridine were purchased from Yingkou Optimal Choice Trade CO., Ltd. (China). $\mathrm{CH}_{3} \mathrm{NH}_{3} \mathrm{I}$ (MAI) was synthesized by the procedure stated previously. ${ }^{40}$

Prior to fabrication, the fluorine-doped tin oxide (FTO, $7 \Omega$ sq. ${ }^{-1}$ ) substrates were carefully patterned and cleaned, as stated in our previous work. ${ }^{36} \mathrm{~A}$ thin compact $\mathrm{TiO}_{2}$ layer $\left(\mathrm{c}-\mathrm{TiO}_{2}\right)$ was deposited on the patterned FTO by spray pyrolysis at $450{ }^{\circ} \mathrm{C}$ by using $0.2 \mathrm{M}$ Ti(rv) bis(ethylacetoacetate)-bis(ethyl acetoacetate)diisopropoxide 1-butanol solution, followed by annealing in air at $450{ }^{\circ} \mathrm{C}$ for $1 \mathrm{~h} .{ }^{36,41}$ The mesoporous $\mathrm{TiO}_{2}$ layer $\left(\mathrm{mp}-\mathrm{TiO}_{2}\right)$ was introduced from a $100 \mu \mathrm{L}$ diluted $\mathrm{TiO}_{2}$ in ethanol by spin coating at $5000 \mathrm{rpm}$ for $30 \mathrm{~s}$. After drying at $125^{\circ} \mathrm{C}$ for $5 \mathrm{~min}$, the $\mathrm{TiO}_{2}$ films were baked at $500{ }^{\circ} \mathrm{C}$ for $20 \mathrm{~min}$ and then cooled to room temperature. Prior to their use, the films were dried again at $500{ }^{\circ} \mathrm{C}$ for $30 \mathrm{~min}$. The thickness of the annealed $\mathrm{TiO}_{2}$ film was around $280 \mathrm{~nm}$, as determined by scanning electron microscopy (SEM; Hitachi S-4800). The $\mathrm{PbI}_{2}$ solution was prepared by dissolving $0.698 \mathrm{~g}$ of $\mathrm{PbI}_{2}(99 \%$, Sigma-Aldrich) in $1.5 \mathrm{~mL}$ of DMF at $70{ }^{\circ} \mathrm{C}$ for $12 \mathrm{~h}$ under static conditions. Before use, the solution was filtered through a $0.22 \mu \mathrm{m}$ PTFE syringe filter. The $\mathrm{PbI}_{2}$ solution $(30 \mu \mathrm{L})$ was spin-coated on the mesoporous $\mathrm{TiO}_{2}$ film at $1300 \mathrm{rpm}$ for $5 \mathrm{~s}$ and $4000 \mathrm{rpm}$ for $20 \mathrm{~s}$, and the annealing-free, wet $\mathrm{PbI}_{2}$ films were then instantly dropped with a solution of $\mathrm{CH}_{3} \mathrm{NH}_{3} \mathrm{I}$ in 2-propanol $\left(150 \mu \mathrm{L}, 20 \mathrm{mg} \mathrm{mL}^{-1}\right)$ and spin-coated at $4000 \mathrm{rpm}$ for $30 \mathrm{~s}$ with a loading time of $30 \mathrm{~s}$. Afterward, the as-prepared films were heated at $100{ }^{\circ} \mathrm{C}$ for $30 \mathrm{~min}$ until the colour changed to dark red. A volume of $40 \mu \mathrm{L}$ of spiro-MeOTAD solution was spin-coated on the $\mathrm{MAPbI}_{3}$ perovskite layer at $4000 \mathrm{rpm}$ for $30 \mathrm{~s}$ to fabricate the hole transporter layer (HTL) in an Ar-filled glovebox $\left(\mathrm{H}_{2} \mathrm{O}\right.$ and $\mathrm{O}_{2}<1$ $\mathrm{ppm}$ ). The spiro-MeOTAD solution was prepared by dissolving $72.3 \mathrm{mg}$ of spiro-MeOTAD in $1 \mathrm{~mL}$ of chlorobenzene, ${ }^{15}$ to which $17.5 \mu \mathrm{L}$ of lithium bis(trifluoromethanesulfonyl)imide (Li-TFSI) solution (520 $\mathrm{mg} \mathrm{mL}^{-1}$ in anhydrous acetonitrile) and $29.0 \mu \mathrm{L}$ of 4-tert-butyl pyridine were added. After being left overnight in the dry dark box, a $120 \mathrm{~nm}$ thick Ag electrode was deposited by thermal evaporation on the spiro-MeOTAD-coated film to complete the fabrication of the cell device. The active area of the devices was determined to be $0.12 \mathrm{~cm}^{2}$ by a shadow mask.

\section{Characterizations}

UV-vis spectra of the perovskite films on mesoporous $\mathrm{TiO}_{2}$ film were obtained by an UV-vis spectrophotometer (Agilent, model Cary 60). X-ray diffraction (XRD) patterns were measured on a Rigaku D/MAX 2400 diffractometer with $\mathrm{Cu} \mathrm{K} \alpha$ radiation at a scan rate of $3^{\circ} \mathrm{min}^{-1}$ under operation condition of $35 \mathrm{kV}$ and $200 \mathrm{~mA}$. A Hitachi S-4800 field-emission scanning electron microscopy (SEM) operated at $10 \mathrm{kV}$ was used to characterize the morphologies of the samples and the cross section of the devices. The root-mean-square roughness (RMS) of the perovskite films were measured by using an atomic force microscopy (AFM, NanoScope III microscope, Digital Instrument) in tapping mode. The $J-V$ curves were measured on a Keithley 2400 source meter under AM $1.5 \mathrm{G}$ illumination $\left(100 \mathrm{~mW} \mathrm{~cm}^{-2}\right)$. The NREL-calibrated Si solar cell with KG-2 filter was employed to adjust light intensity into 1 sun illumination. A black aperture mask with the area of $0.09 \mathrm{~cm}^{2}$ was used to prevent scattered light during $J-V$ measurement. ${ }^{40}$ The external quantum efficiency spectra were recorded on a SM-250 Hyper Monolight system. Time-resolved photoluminescence (PL) decay spectra of glass $/ \mathrm{MAPbI}_{3} / \mathrm{PMMA}$ films were measured on a steady-state and time-resolved fluorescence spectrofluorometer (PTI model, QM/ $\mathrm{TM} / \mathrm{IM}$ ) with a $579 \mathrm{~nm}$ photoluminescence dye for excitation at room temperature, where poly(methyl methacrylate) (PMMA) serves as protective layer for perovskite films. Impedance spectroscopy (IS) was performed on an impedance/gain-phase analyzer (Solartron SI 1260) with a bias voltage of $0.7 \mathrm{~V}$, a modulation amplitude of $10 \mathrm{mV}$, and a frequency ranging from $100 \mathrm{kHz}$ to $1 \mathrm{~Hz}$ under 1 sun illumination. 


\section{Results and discussion}

Here, a two-step sequential deposition method was employed to prepare the perovskite thin film, as shown in Fig. 1(a). We have systematically explored the effects of the $\mathrm{PbI}_{2}$ precursor film qualities on the crystal growth kinetics, film morphology and corresponding photovoltaic performance of perovskites. Fig. 1(b) shows the photographs of the $\mathrm{PbI}_{2}$, as-prepared $\mathrm{MAPbI}_{3}$ and thermal-annealed $\mathrm{MAPbI}_{3}$ prepared from different $\mathrm{PbI}_{2}$ precursor films. The annealing-free, wet $\mathrm{PbI}_{2}\left(\mathrm{w}-\mathrm{PbI}_{2}\right)$ films were pale yellow, while the well-crystallized and compact $\mathrm{PbI}_{2}\left(\mathrm{c}-\mathrm{PbI}_{2}\right)$ film prepared by conventional method of $70{ }^{\circ} \mathrm{C}$-treated was dark yellow. Both of them were smooth. For comparison, highcrystallized porous $\mathrm{PbI}_{2}\left(\mathrm{p}-\mathrm{PbI}_{2}\right)$ films were prepared by an antisolvent (IPA) extraction method, which was confirmed by the $\mathrm{XRD}$ results. The increased baseline of the UV-vis absorption spectra in Fig. 2(a) reflected the stronger light scattering effect associated with a rougher $\mathrm{p}-\mathrm{PbI}_{2}$ morphology, ${ }^{23,40}$ which was confirmed by the reduced transmittance of the film (Fig. 2(b)). With tens of seconds after dropping of MAI solution, the pale yellow $\mathrm{w}-\mathrm{PbI}_{2}$ immediately turned to dark red, indicating the fast conversion of $\mathrm{PbI}_{2}$ to perovskites. This may be attributed to the fact that MAI has a stronger binding capacity than DMF molecules with $\mathrm{Pb}^{2+}$ in the $\mathrm{w}-\mathrm{PbI}_{2}$ films and the former can substitute the latter to self-assemble into perovskite crystals. However, there was only a slight colour change for the compact c- $\mathrm{PbI}_{2}$ precursor films with short dropping time, which was similar to the results in the previous reports. ${ }^{24,27}$ The $\mathrm{p}-\mathrm{PbI}_{2}$ films with a larger specific area can also facilitate its reaction with MAI because more reaction sites are provided, which is consistent with the previous literatures. ${ }^{31,37}$ The corresponding absorption spectra of the prepared perovskite films without and with annealing at $100{ }^{\circ} \mathrm{C}$ for $30 \mathrm{~min}$ are shown in Fig. 2(c) and (d), respectively. Upon annealing, the UV-vis spectra of all samples show a typical $\mathrm{MAPbI}_{3}$ absorbance. The absorbance of $\mathrm{MAPbI}_{3}$ from $\mathrm{p}-\mathrm{PbI}_{2}$ precursor films slightly increases in contrast to that of $\mathrm{w}-\mathrm{PbI}_{2}$ fabricated perovskites, which is due to the thicker capping layer of $\mathrm{p}-\mathrm{PbI}_{2}$-fabricated perovskites, as shown in Fig. S1 in the ESI. $\dagger$ The change in the thickness of the capping layer can be attributed to the volume expansion in the two-step sequential deposition process based on well-crystallized and compact $\mathrm{PbI}_{2} \cdot{ }^{13,23}$
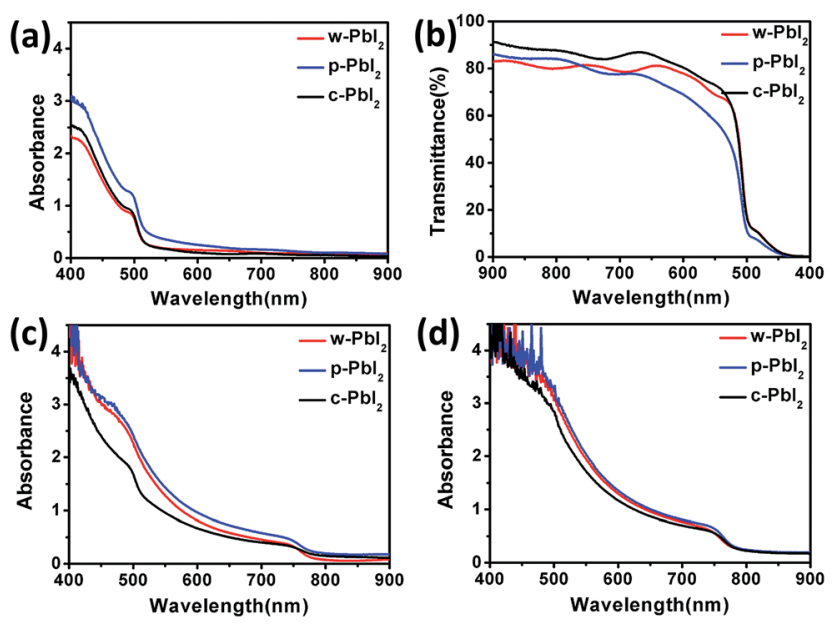

Fig. 2 UV-vis absorption spectra (a) and transmittance spectra (b) of the various $\mathrm{Pbl}_{2}$ precursor films on mesoporous $\mathrm{TiO}_{2}$ film. UV-vis absorption spectra of the corresponding annealing-free (c) and annealed (d) perovskite films prepared from their respective precursor films.

Fig. 3(a) displays the XRD patterns of $\mathrm{PbI}_{2}$ thin films deposited on the mesoporous $\mathrm{TiO}_{2}$ films, and all the diffraction patterns are plotted at the same intensity scale. All of the XRD patterns of $\mathrm{PbI}_{2}$ films are exactly consistent with $\mathrm{PbI}_{2}$ peaks at $12.6^{\circ}$ and $38.0^{\circ},{ }^{15,31}$ which correspond to $\mathrm{PbI}_{2}$ (001) peak and $\mathrm{PbI}_{2}$ (003) peak, respectively. For the $\mathrm{w}-\mathrm{PbI}_{2}$ film, the intensities of $\mathrm{PbI}_{2}$ (001) diffraction peak are obviously quenched, which suggests that the presence of high boiling DMF solvent in the as-prepared wet $\mathrm{PbI}_{2}$ film retards the growth of $\mathrm{PbI}_{2}$ crystals. The retarded effect of DMF on the crystal growth of $\mathrm{PbI}_{2}$ films could be ascribed to its coordination ability with $\mathrm{Pb}^{2+}$, which is similar to a strongly coordinative solvent of DMSO. ${ }^{10,13}$ However, for the $\mathrm{c}-\mathrm{PbI}_{2}$ film, the increased intensity of $\mathrm{PbI}_{2}$ (001) peak, indicating the increase in the crystallinity of the $\mathrm{PbI}_{2}$ film, is owing to the evaporation of the coordinative solvent of DMF in $\mathrm{PbI}_{2}$ film via a $70{ }^{\circ} \mathrm{C}$ thermal annealing. ${ }^{\mathbf{1 0}, 15}$ The highest $\mathrm{PbI}_{2}$ (001) diffraction peak of $\mathrm{p}-\mathrm{PbI}_{2}$ films can be ascribed to an effective extraction of residual DMF by an anti-solvent of IPA molecules. ${ }^{31}$ Additionally, it is quite effective to assess the crystallinity of the samples by the full width at half maximum

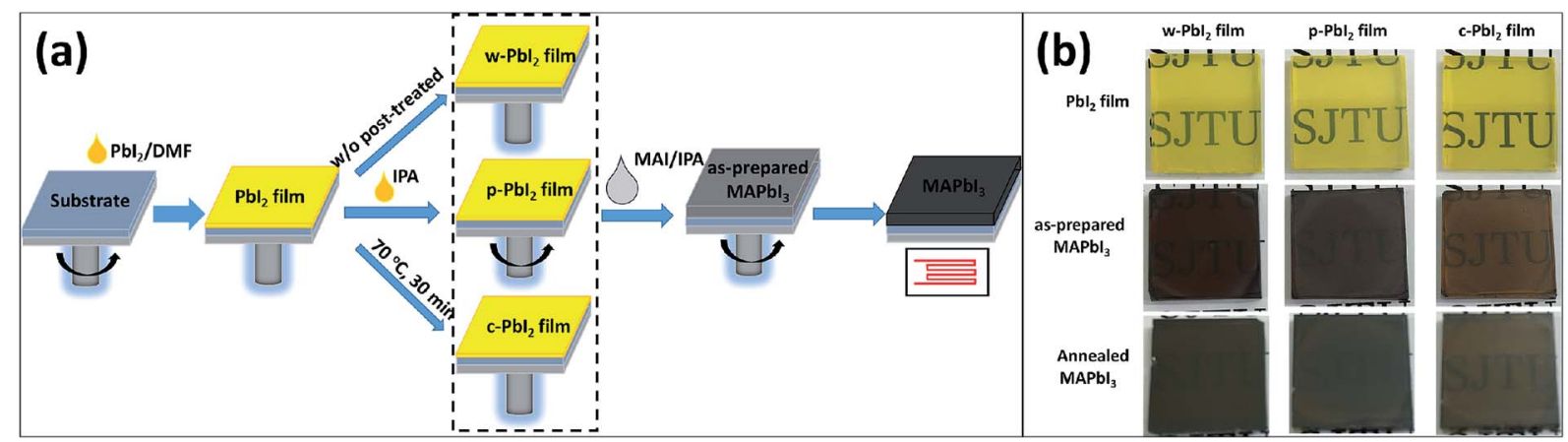

Fig. 1 Schematic (a) of the two-step sequential drop-coating method for perovskite films fabrication. Photographs (b) of various $\mathrm{Pbl}_{2}$ precursor films on mesoporous $\mathrm{TiO}_{2}$ film, and the corresponding annealing-free and/or annealed perovskite films. 

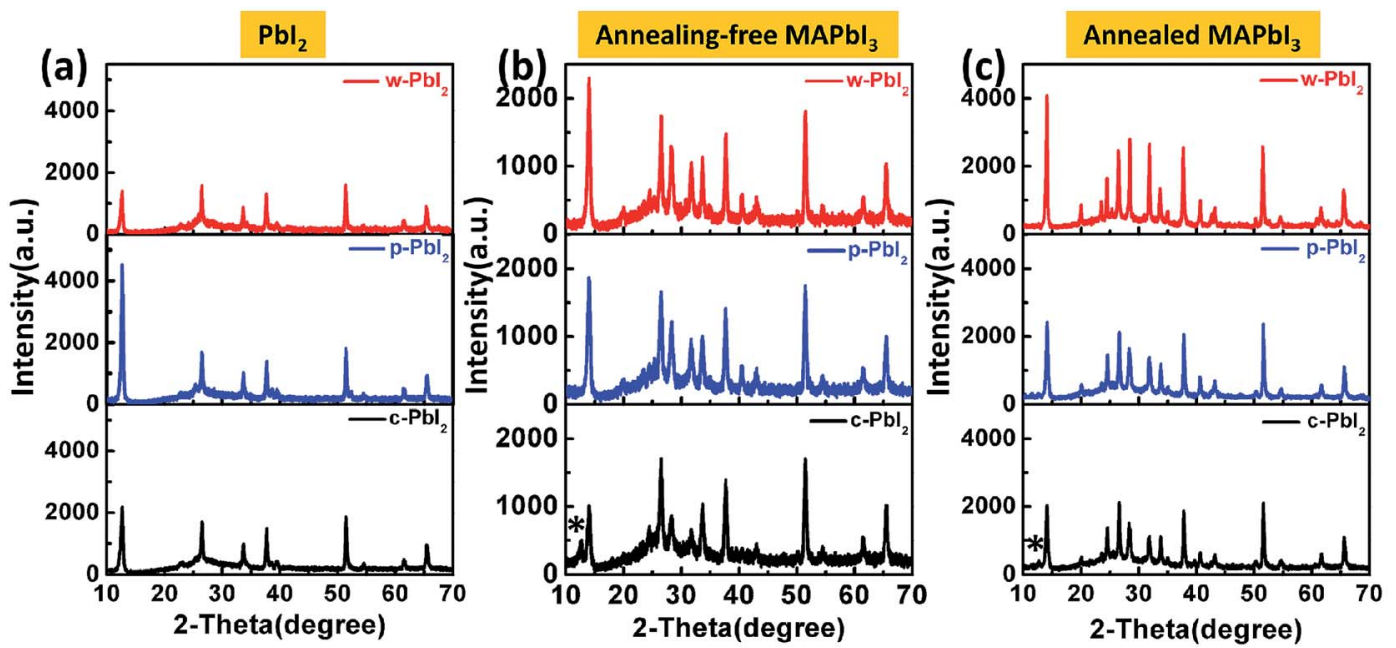

Fig. 3 XRD patterns of the various $\mathrm{Pbl}_{2}$ precursor films (a), the perovskite films prepared from their respective $\mathrm{Pbl}_{2}$ precursor films without thermal annealing (b), and the perovskite films with thermal annealing (c). Asterisks indicate the peaks ascribed to $\mathrm{Pbl}_{2}$.

(FWHM) of characteristic diffraction peaks. FWHM of $\mathrm{PbI}_{2}(001)$ diffraction peak of the three types of $\mathrm{PbI}_{2}$ films are extracted from the XRD patterns, as summarized in Table S1. $\dagger$ It is well known that the smaller FWHM of diffraction peak generally means the higher crystallinity. Largest FWHM of the w-PbI ${ }_{2}$ film indicates lowest crystallinity, which is consistent with the results obtained from the diffraction peak intensity of $\mathrm{PbI}_{2}$ (001). Fig. 3(b) and (c) presents the XRD patterns of the perovskite films with and without annealing. The XRD patterns show that all perovskites exhibited a tetragonal perovskite structure with $I 4 \mathrm{~cm}$ symmetry and a high phase purity, which matches well with the results reported in other literatures. ${ }^{36}$ The XRD patterns shown in Fig. 3(b) indicates a partial conversion of $\mathrm{MAPbI}_{3}$ and a large amount of $\mathrm{PbI}_{2}$ residue was still left for the dry c- $\mathrm{PbI}_{2}$ films. The residual $\mathrm{PbI}_{2}$ cannot be converted to perovskites even after high-temperature annealing, as to obvious $\mathrm{PbI}_{2}$ peaks at $12.6^{\circ}$ (Fig. 3(c)), which can be explained by considering that the volume expansion inhibits the reaction of MAI with dense $\mathrm{PbI}_{2}$ films. ${ }^{13,23}$ Intriguingly, we found that the annealing-free, wet $\mathrm{PbI}_{2}$ films accelerate the reaction between $\mathrm{PbI}_{2}$ and MAI to form perovskite. Tens of seconds at room temperature is effective and sufficient to transform $\mathrm{PbI}_{2}$ into dense, uniform and dark-brown well-crystallized $\mathrm{MAPbI}_{3}$ films, which can be attributed to the retarded crystallization of $\mathrm{w}-\mathrm{PbI}_{2}$ and a direct molecular exchange of DMF molecules intercalated in $\mathrm{PbI}_{2}$ with MAI. Upon annealing, the crystallinity of perovskites significantly increases, as shown in Fig. 3(c). The result is consistent with the trend in $\mathrm{FWHM}$ of $\mathrm{MAPbI}_{3}(110)$ diffraction peak (Table $\mathrm{S} 1 \dagger$ ). In addition, the well-crystallized $\mathrm{p}-\mathrm{PbI}_{2}$ films can also facilitate the conversion of $\mathrm{PbI}_{2}$ to $\mathrm{MAPbI}_{3}$, which can be ascribed to the fact that a porous microstructure of $\mathrm{PbI}_{2}$ provides sufficient reaction sites and reduces resistance of the volume expansion during MAI intercalation. Generally, the perovskite film fabricated from $\mathrm{w}-\mathrm{PbI}_{2}$ exhibits highest crystallinity. The UV-vis spectra of $\mathrm{MAPbI}_{3}$ films all show broad absorptions with band edge around $775 \mathrm{~nm}$ (Fig. 2(d)). A high light harvesting perovskite layer can be achieved by wet $\mathrm{PbI}_{2}$ precursor films, which is due to the increased crystallinity and complete conversion of the $\mathrm{PbI}_{2}$ films to $\mathrm{MAPbI}_{3}$.

It is well known that for a two-step sequential deposition, the perovskite film quality and morphology greatly depend on the processing of the initial $\mathrm{PbI}_{2}$ film. ${ }^{23,37,42}$ Thus, we investigated the surface morphology of the perovskites fabricated from various $\mathrm{PbI}_{2}$ films by scanning electron microscopy (SEM). Fig. 4(a-c) shows the typical SEM images of top views of the $\mathrm{PbI}_{2}$ precursor films. In the c- $\mathrm{PbI}_{2}$ case, $\mathrm{PbI}_{2}$ was found to form

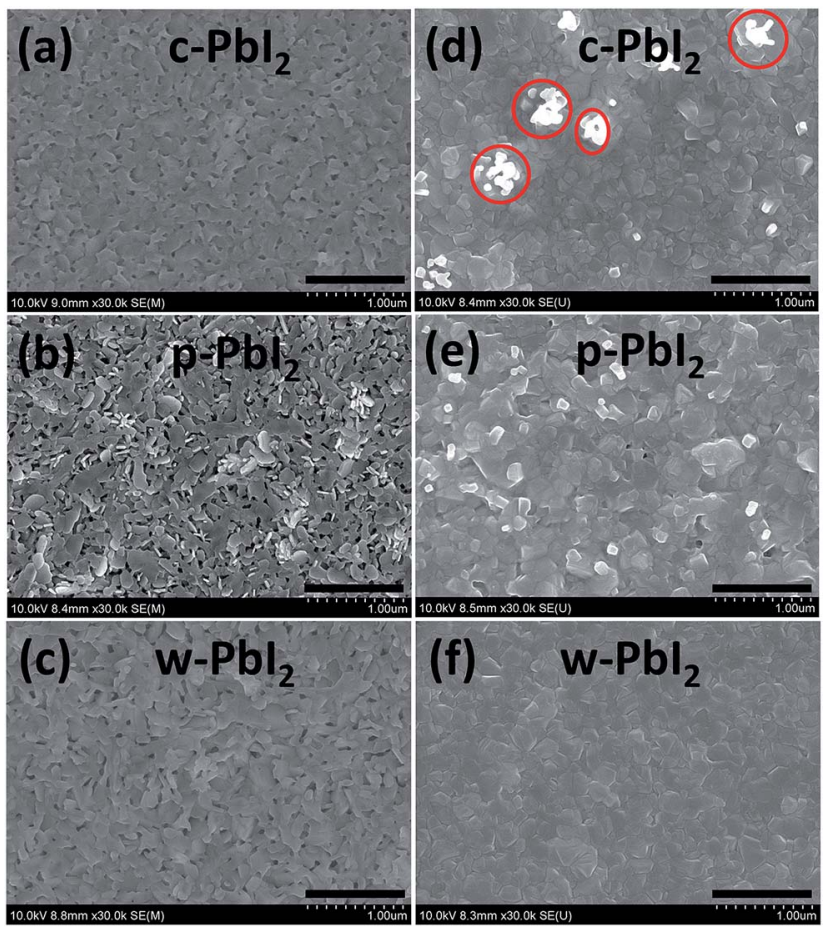

Fig. 4 Typical SEM images of $(a-c) c-P b l_{2}, p-P_{2}$ and $w-P_{2}$ precursor films, respectively. And $(d-f)$ the corresponding annealed $\mathrm{MAPbl}_{3}$ films prepared from their respective precursor films as indicated. The scale bars are $1 \mu \mathrm{m}$. 
closely packed layered crystals with hundreds of nanometers due to the improved crystallization after $70{ }^{\circ} \mathrm{C}$ annealing. In contrast, the $\mathrm{w}-\mathrm{PbI}_{2}$ film has a very different morphology since the presence of the coordinative solvent of DMF, where a much more uniform surface with a small crystal sizes, loose crystals and few pinholes is observed. However, the morphology of the $\mathrm{p}-\mathrm{PbI}_{2}$ films becomes coarser, which is consistent with the higher absorption baseline of the p- $\mathrm{PbI}_{2}$ films (Fig. 2(a)). There are also much larger holes distributed on the surface of the films, which result from the fast formation of $\mathrm{PbI}_{2}$ due to the effective extraction of DMF molecules by an anti-solvent of IPA from the as-spin-coated $\mathrm{PbI}_{2}$ film. Fig. $4(\mathrm{~d}-\mathrm{f})$ shows the typical SEM images of the annealed $\mathrm{MAPbI}_{3}$ films converted from various $\mathrm{PbI}_{2}$ films after the second dropping step. The surface morphologies of perovskites, including grain size, surface roughness and coverage, that converted from three types of $\mathrm{PbI}_{2}$ precursor film are obviously different. The $\mathrm{MAPbI}_{3}$ perovskite film fabricated by c- $-\mathrm{PbI}_{2}$ film shows large variations in crystallite size, with islands of sub-micron size situating all over the surface, which is due to the inhibited intercalation reaction of MAI into closely packed $\mathrm{PbI}_{2}$ crystals skeleton. Although the average thickness of the perovskites seems to be uniform, the presence of these random and disordered structures on the surface (marked by red circles, Fig. 4(d)) increases the possibility of current leakage occurring through the thin HTM layer to the electrode. ${ }^{32,43}$ In contrast, we are able to produce extremely dense and homogeneous and pinholes-free perovskite films by using an annealing-free, wet $\mathrm{PbI}_{2}$ films (Fig. 4(f)), which benefit from the in situ substitution reaction of coordinative solvent (DMF) molecules by the MAI molecules in low crystallization of $\mathrm{w}-\mathrm{PbI}_{2}$ film. The crystal grains of the $\mathrm{w}-\mathrm{PbI}_{2}-$ based perovskite film are larger than those of the c- $\mathrm{PbI}_{2}$ and p$\mathrm{PbI}_{2}$-based perovskite film, as shown in Fig. $\mathrm{S} 2$ in the ESI. $\dagger$ The average grain size of perovskites prepared from c- $\mathrm{PbI}_{2}, \mathrm{w}-\mathrm{PbI}_{2}$ and $\mathrm{p}-\mathrm{PbI}_{2}$ film are approximately 127, 173 and $149 \mathrm{~nm}$, respectively. However, the $\mathrm{MAPbI}_{3}$ film (Fig. 4(e)) fabricated from $\mathrm{p}-\mathrm{PbI}_{2}$ film shows a significantly different morphology of an un-continuous and rough surface, which is due to the nonuniform, rough and macro-porous surface character of $\mathrm{p}-\mathrm{PbI}_{2}$ precursor film. A similar result can also be obtained from the SEM images of as-prepared $\mathrm{MAPbI}_{3}$ without annealing (Fig. S3 $\uparrow$ ). The cross-sectional SEM image of perovskites coated on $\mathrm{mp}-\mathrm{TiO}_{2}$ shows that the $\mathrm{MAPbI}_{3}$ material is uniformly infiltrated into the mesopores of the $\mathrm{TiO}_{2}$ film (Fig. S1 $\dagger$ ). The differences in surface morphology of the three films are attributed to the various reaction characteristics between $\mathrm{PbI}_{2}$ films and MAI. The nucleation density is much higher for the films processed from well-crystallized $\mathrm{PbI}_{2}$ film, which tends to form a large amount of relatively small crystals and disordered structures. In contrast, for w- $\mathrm{PbI}_{2}$ film, which reacts with MAI in a slower way due to the low crystallization of $\mathrm{PbI}_{2}$, the low nucleation density at initial step is favourable to form large grains at the later crystallization stage. ${ }^{32}$ Thus, the $\mathrm{PbI}_{2}$ can efficiently react with MAI by an in situ molecular exchange of DMF molecules with MAI in w- $\mathrm{PbI}_{2}$ films, rather than a reaction of MAI with porous $\mathrm{PbI}_{2}$ film formed by the extraction of DMF molecules. ${ }^{13,24}$ And, the perovskite films fabricated by ${ }^{\mathrm{w}}-\mathrm{PbI}_{2}$ precursor film can retain the uniform and smooth surface of the $\mathrm{PbI}_{2}$ film character. Meanwhile, DMF molecules extracted by IPA "activate" the $\mathrm{PbI}_{2}$ film and facilitate the reaction with MAI, reported in the previous literature. ${ }^{40}$ Those special phenomena of surface morphologies are also observed in atomic force microscopy (AFM) images, as shown in Fig. S4 in the ESI. $\uparrow$ The root-mean-square roughnesses (RMS) of the films were also determined by AFM. The RMS values of perovskites prepared by w- $-\mathrm{PbI}_{2}, \mathrm{p}-\mathrm{PbI}_{2}$ and c- $\mathrm{PbI}_{2}$ are 19.5, 54.1 and $39.9 \mathrm{~nm}$, respectively. The film prepared from $\mathrm{w}-\mathrm{PbI}_{2}$ exhibits the lowest surface roughness. In general, a smoother surface is accompanied with a higher surface coverage, which is essential for the high photovoltaic performance of perovskite solar cells. ${ }^{18,36}$

As we all known, the crystallinity and morphology of the perovskite film determine the photovoltaic performance of the cell device. Generally, non-uniform, pinhole surface causes current leakage and defects cause the increment of trapping sites for carrier recombination. Fig. 5(a) shows the typical photocurrent density-voltage $(J-V)$ curves of $\mathrm{MAPbI}_{3}$ devices fabricated by using different $\mathrm{PbI}_{2}$ precursor films in the same batch under simulated 1 sun illumination. The typical crosssectional SEM images of the fabricated perovskite solar cell

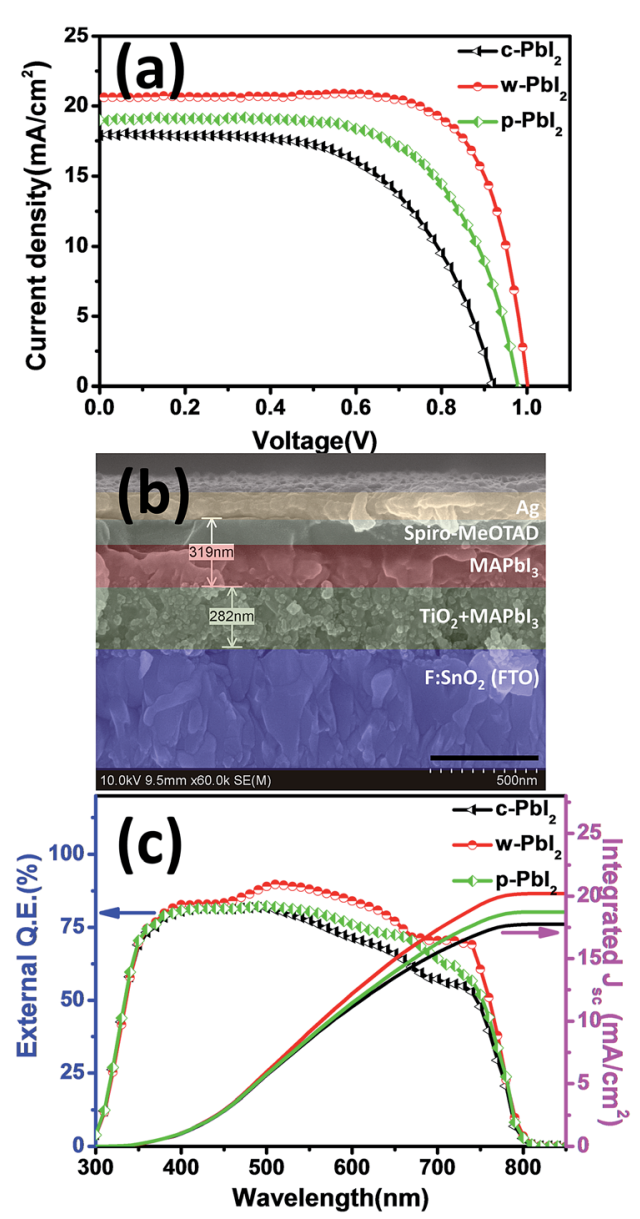

Fig. 5 Typical J-V curves (a), cross-sectional SEM image (b) and external quantum efficiency (EQE) (c) of the cell device of $\mathrm{MAPb}_{3}$ solar cells fabricated from various $\mathrm{Pbl}_{2}$ precursor films. The scale bars are $500 \mathrm{~nm}$. 
are presented Fig. 5(b). Statistical photovoltaic parameters of all these three types of devices fabricated from various $\mathrm{PbI}_{2}$ precursor films are summarized in Table 1 . The data were obtained from 20 individual cells. A correlation between film qualities and the device parameters is observed, as evident from the substantial improvement in photovoltaic performance in device prepared using a w- $\mathrm{PbI}_{2}$ films. In the case of $\mathrm{c}-\mathrm{PbI}_{2}$, the device exhibits the PCE of $9.80 \%$, along with a $J_{\mathrm{sc}}$ of $17.90 \mathrm{~mA}$ $\mathrm{cm}^{-2}, V_{\mathrm{oc}}$ of $0.921 \mathrm{~V}$, and $\mathrm{FF}$ of 0.594 . The cell efficiency increases significantly when $\mathrm{w}-\mathrm{PbI}_{2}$ is used. The efficiency for w$\mathrm{PbI}_{2}$-based cell is increased to $15.28 \%$ with a $J_{\text {sc }}$ of $20.63 \mathrm{~mA}$ $\mathrm{cm}^{-2}, V_{\mathrm{oc}}$ of $1.002 \mathrm{~V}$, and $\mathrm{FF}$ of 0.739 . The efficiency enhancement is largely determined by the increased $J_{\text {sc }}$ value, which can be attributed to the complete conversion of $\mathrm{PbI}_{2}$ into $\mathrm{MAPbI}_{3}$, increased $\mathrm{MAPbI}_{3}$ crystallinity, and light absorption of perovskites and improved film morphologies of perovskites. Especially, the unconverted $\mathrm{PbI}_{2}$ in the $\mathrm{MAPbI}_{3}$ film prepared from c$\mathrm{PbI}_{2}$ will increase the charge transfer resistance since the unsuitable energy level of $\mathrm{PbI}_{2}$. The poor $V_{\mathrm{oc}}$ and $\mathrm{FF}$ values for the devices based on c- $\mathrm{PbI}_{2}$ result from the bad morphology of perovskite film, in which the presence of these islands of submicron crystallites on the perovskites surface (Fig. 4(d)) increases the number of current leakage paths. However, when $\mathrm{p}-\mathrm{PbI}_{2}$ is used, all device parameters are increased comparing with c- $\mathrm{PbI}_{2}$-based device, with a typical $J_{\mathrm{sc}}$ of $19.00 \mathrm{~mA} \mathrm{~cm}{ }^{-2}, V_{\mathrm{oc}}$ of $0.979 \mathrm{~V}$, and $\mathrm{FF}$ of 0.652 , yielding an average efficiency of $12.13 \%$. This is probably due to the complete conversion of $\mathrm{PbI}_{2}$ films and improved crystallinity of perovskites and increased light absorption of perovskite layer. The $V_{\mathrm{oc}}$ and $\mathrm{FF}$ values for the devices based on $\mathrm{w}-\mathrm{PbI}_{2}$ are significantly larger than those of the cells fabricated from $\mathrm{p}-\mathrm{PbI}_{2}$ precursor film, which is ascribable to the lack of leakage paths in the homogenous perovskite film in consideration of no $\mathrm{PbI}_{2}$ residue found in the p- $\mathrm{PbI}_{2}$-prepared $\mathrm{MAPbI}_{3}$ film (as XRD in Fig. 1). The increased crystal size in perovskites film prepared from $\mathrm{w}-\mathrm{PbI}_{2}$ film can also reduce charge trapping and recombination at grain boundaries, thereby improving the $\mathrm{FF}$ and $V_{\text {oc }}$ owing to better film formation and hence a reduction in the number of shunting paths..$^{32,43}$ Additionally, the drop in cell performance is mostly consistent with its much shorter photoluminescence (PL) carrier lifetime and reduced recombination resistance, which is due to a coarser, un-continuous and pinhole perovskites, as the below discussed. Furthermore, the results clearly indicated that the $\mathrm{w}-\mathrm{PbI}_{2}$-based devices gave better reproducibility due to their high-quality perovskite layer, whereas the c-
$\mathrm{PbI}_{2}$-based devices had a broad distribution of efficiencies (Fig. S5 $†$ ). The external quantum efficiency (EQE) for the devices are also compared (Fig. 5(c)). The integrated current densities of the devices fabricated from c- $\mathrm{PbI}_{2}, \mathrm{w}-\mathrm{PbI}_{2}$ and $\mathrm{p}-\mathrm{PbI}_{2}$ precursor films, calculated from the EQE spectra, are 17.75, 20.22 and $18.74 \mathrm{~mA} \mathrm{~cm} \mathrm{~cm}^{-2}$, respectively. The integrated $J_{\mathrm{sc}}$ values are consistent with the $J_{\text {sc }}$ value obtained from the $J-V$ curves. The EQE intensity dropped at a wavelength longer than $760 \mathrm{~nm}$. This result is consistent with other literature reports. ${ }^{9}$ It may be owing to the perovskite film having a strong absorption in the visible spectrum (Fig. 2(d)). The EQE of w-PbI ${ }_{2}$-based $\mathrm{MAPbI}_{3}$ solar cell has reached up to $80 \%$ at a wide spectra range, and is higher than those of cell devices fabricated by $\mathrm{c}-\mathrm{PbI}_{2}$ and $\mathrm{p}-\mathrm{PbI}_{2}$ precursor film. The optimized PCE of the devices prepared from w- $\mathrm{PbI}_{2}$ film is $15.49 \%$ with a $J_{\mathrm{sc}}$ of $20.74 \mathrm{~mA} \mathrm{~cm}^{-2}, V_{\text {oc }}$ of $1.004 \mathrm{~V}$, and $\mathrm{FF}$ of 0.744 , and its $J_{\mathrm{sc}}$ value is consistent with the integrated $J_{\mathrm{sc}}$ values of $20.20 \mathrm{~mA} \mathrm{~cm}{ }^{-2}$ calculated from EQE spectrum (Fig. $S 6 \dagger$ ). The stable power output of this champion cell is about $15.08 \%$, which is closed to its corresponding maximum efficiency value.

The perovskite materials have strong photoluminescence (PL), which is directly associated with the charge recombination. To further reflect the quality of the perovskite films fabricated from various $\mathrm{PbI}_{2}$ film, steady-state PL (SS-PL) and time-resolved PL (TR-PL) decay were characterized, and the corresponding spectra of protective layer (PMMA) coated perovskite films, which were deposited on insulating mesoporous $\mathrm{Al}_{2} \mathrm{O}_{3}\left(\mathrm{mp}-\mathrm{Al}_{2} \mathrm{O}_{3}\right) / g$ lass substrate, are shown in Fig. 6(a). Generally, high-quality perovskite films are associated with high PL efficiency and slow PL decay with reduced non-radiative recombination.,44 The emission peaks corresponding to the maximum PL intensity are located at about $\sim 775 \mathrm{~nm}$ corresponds to the band gap of about $1.6 \mathrm{eV}$, which is consistent with the previously reported results. ${ }^{45,46}$ Several reports have revealed that morphological changes affect the optical properties of the perovskite films. Larger crystallite size induces a smaller band gap and longer lifetime, which is mainly due to the enhancement of the local order of the crystalline structure. ${ }^{46-48}$ The PL emission peaks of w-PbI ${ }_{2}$-prepared perovskite film $(776 \mathrm{~nm})$ slightly shift to longer wavelength compared with $\mathrm{c}-\mathrm{PbI}_{2}$ prepared perovskite film $(775 \mathrm{~nm})$. Since the PL of perovskites is expected to occur due to the recombination of localized excitons, the red-shift of PL spectra can be attributed to less localized exciton states in large crystals of $\mathrm{w}-\mathrm{PbI}_{2}$-prepared

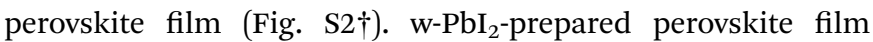

Table 1 Mean values with standard deviation (STDEV) of photovoltaic performance parameters (PCE, the $J_{\mathrm{sc}}, V_{\mathrm{oc}}$ and FF) extracted from $J-V$ measurements for the devices under 1 sun illumination (AM 1.5G, $100 \mathrm{~mW} \mathrm{~cm}^{-2}$ ). Each group contains more than 20 individual samples. Best results of each type of devices prepared with various $\mathrm{Pbl}_{2}$ films are listed in bracket

\begin{tabular}{|c|c|c|c|c|}
\hline $\mathrm{PbI}_{2}$ films & $J_{\mathrm{sc}}{ }^{a}\left[\mathrm{~mA} \mathrm{~cm}^{-2}\right]$ & $V_{\mathrm{oc}}^{b}[\mathrm{~V}]$ & $\mathrm{FF}^{c}$ & $\mathrm{PCE}^{d}[\%]$ \\
\hline $\mathrm{c}-\mathrm{PbI}_{2}$ & $16.61 \pm 0.87(17.72)$ & $0.941 \pm 0.024(0.958)$ & $0.625 \pm 0.021(0.616)$ & $9.76 \pm 0.46(10.45)$ \\
\hline $\mathrm{w}-\mathrm{PbI}_{2}$ & $20.49 \pm 0.59(20.74)$ & $1.011 \pm 0.009(1.004)$ & $0.735 \pm 0.020(0.744)$ & $15.22 \pm 0.17(15.49)$ \\
\hline $\mathrm{p}-\mathrm{PbI}_{2}$ & $17.99 \pm 0.75(18.43)$ & $0.985 \pm 0.013(0.994)$ & $0.658 \pm 0.020(0.682)$ & $11.65 \pm 0.45(12.49)$ \\
\hline
\end{tabular}

${ }^{a}$ Short-circuit photocurrent. ${ }^{b}$ Open-circuit photovoltage. ${ }^{c}$ Fill factor. ${ }^{d}$ Power conversion efficiency. 

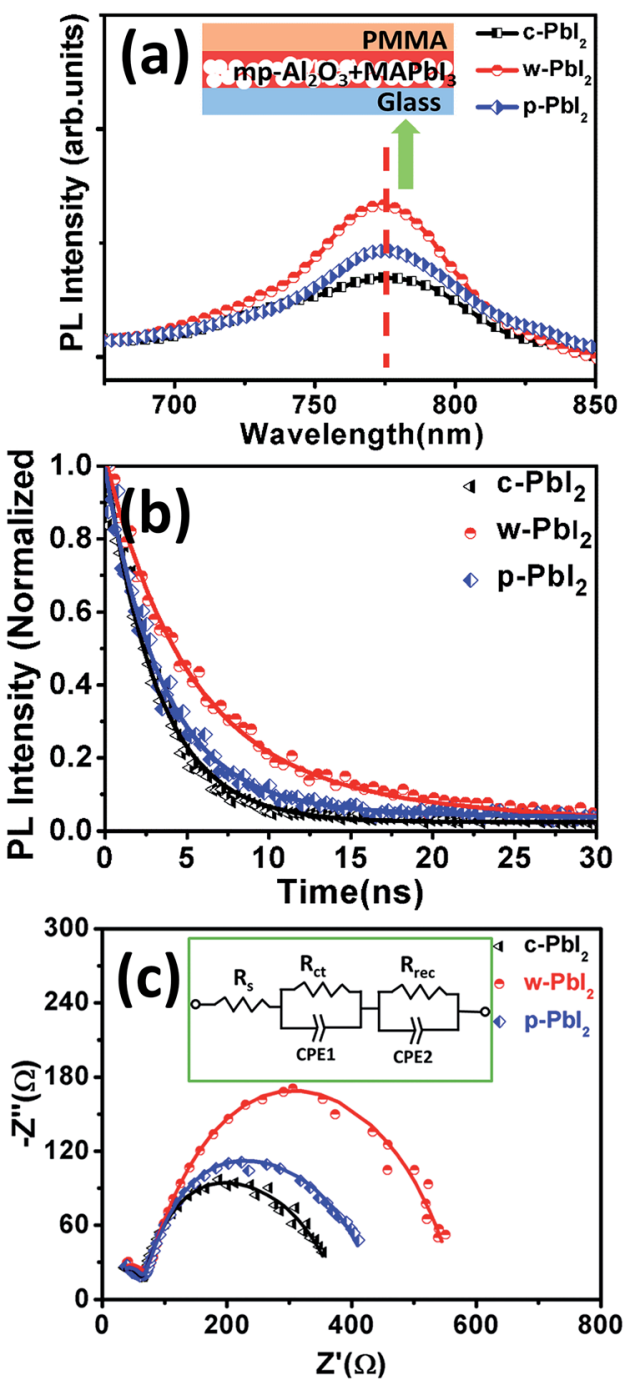

Fig. 6 Typical steady-state photoluminescence (PL) spectra (a) and time-resolved PL decay spectra (b) of the perovskite films fabricated from $\mathrm{c}-\mathrm{Pbl}_{2}, \mathrm{w}-\mathrm{Pbl}_{2}$ and $\mathrm{p}-\mathrm{Pbl}_{2}$ respectively. Nyquist plots (c) of the devices fabricated from various $\mathrm{MAPb}_{3}$ films under 1 sun light illumination condition with $0.7 \mathrm{~V}$ bias voltage, and the fitted result (solid line) is fitted to experimental data (symbols) using the equivalent circuit for fitting in the inset.

shows the highest PL intensity, indicating the non-radiative recombination caused by defects or trapping sites in the film, are greatly suppressed. The TR-PL decays are presented in Fig. 6(b). All curves are well fitted with a double-exponential decay function: $I(t)=A_{1} \times \exp \left(-t / \tau_{1}\right)+A_{2} \times \exp \left(-t / \tau_{2}\right)$, where $t$ is the time after optical excitation, $I(t)$ is the luminescence intensity at time $t, A_{1}$ and $A_{2}$ are coefficients, and $\tau_{1}$ and $\tau_{2}$ are the fast and slow decay lifetimes, respectively. Similarly, as obtained from the results of the SS-PL spectra, TR-PL curves clearly show that the PL lifetime is highest for the sample obtained by using $\mathrm{w}-\mathrm{PbI}_{2}$ film. The steady $\mathrm{PL}$ and TR-PL measurements indicate that the non-radiative recombination channels are effectively inhibited in $\mathrm{w}$ - $\mathrm{PbI}_{2}$-based perovskite film. This can be ascribed to the improvement in the crystallization of the perovskite films, the increase in the grain size of perovskites with reduced grain boundaries in the bulk perovskites and the optimization of film morphology. The improved crystallinities size and crystallinity of the perovskite films will decrease the density of the defects and reduce the shunt paths of charge transfer. The crystal quality of perovskites is known to intensely affect the efficiency of photogenerated carrier separation and charge transport. ${ }^{49}$ It also affects the photovoltaic performance of devices because defects in the crystals create shorting sites and trapping sites for charge recombination.

Impedance spectroscopy (IS) can be used to decouple physical processes with various characteristic time scales in solar cells, such as the charge conductivity, carrier recombination resistance, and the chemical capacitance. ${ }^{50-54}$ In order to deeply understand the variation in the device performance, especially on $V_{\mathrm{oc}}$, Nyquist plots (Fig. 6(c)) of the perovskite solar cells were measured under 1 sun light illumination condition, followed by the method in our previous work. ${ }^{36}$ The obtained IS spectra only contain a two arcs. As in a previous report, ${ }^{50,53}$ there is no distinct transmission line behaviour under 1 sun illumination in this experiments. The absence of transmission line behaviour, which results from electron transport resistance, is likely because of the thin $\mathrm{TiO}_{2}$ films employed. As a result, the low electron transport resistance does not allow the sufficient resolution of any transmission line feature. Therefore, the simplified equivalent electrical circuit model is used to fit the experimental data, as shown in Fig. 6(c). The fitted curve is in good agreement with the experimental data. In this equivalent circuit model, the series resistance $R_{\mathrm{s}}$, representing the ohmic resistance due to wiring, $\mathrm{Ag}$ and FTO electrodes measured at high frequency, is equal to the value of high frequency intercept on the real axis. Because of the same device architectures, there is no significantly difference in $R_{\mathrm{s}}$ for various cell devices fabricated from c- $-\mathrm{PbI}_{2}(15.8 \Omega), \mathrm{c}-\mathrm{PbI}_{2}(16.6 \Omega)$ and c- $\mathrm{PbI}_{2}(16.4$ $\Omega$ ). The high-frequency arc reflects the carrier transport in selective electrodes (SE), which is ascribed to the parallel association of $R_{\mathrm{ct}} \cdot R_{\mathrm{ct}}$ resistance is influenced by transport resistance at the HTL (spiro-MeOTAD) and ETL $\left(\mathrm{TiO}_{2}\right)$, but also by the charge transfer resistance at the SE-perovskite interfaces. ${ }^{53-56} \mathrm{In}$ most cases, the current between two different materials undergoes a resistive effect, originating a charge transfer resistance at the interface. As the selective-electrode material (ETL and HTL) and their deposition process are analogous for all samples, we can suppose that $R_{\mathrm{ct}}$ is mainly governed by the charge transfer resistance at the HTM-perovskite interface. Moreover, lower $R_{\mathrm{ct}}$ has been also obtained for the $\mathrm{w}-\mathrm{PbI}_{2}$-based device $(48.5 \Omega)$ than those of the c-PbI ${ }_{2}$-based $(58.9 \Omega)$ and c$\mathrm{PbI}_{2}$-based device $(59.1 \Omega)$, which can be attributed to the uniform and ultra-smooth surface of perovskite film prepared from $\mathrm{w}-\mathrm{PbI}_{2}$ precursor film. This fact can explain the slightly increased $\mathrm{FF}$ of this c- $\mathrm{PbI}_{2}$-based sample in comparison with that of the other samples, as this $R_{\mathrm{ct}}$ resistance contributes to the total series resistance. The low-frequency arc represents a recombination process, originating from the parallel association of recombination resistance $R_{\text {rec }}$, in parallel with a dielectric relaxation capacitance and closely related to the perovskite layer. ${ }^{55-58}$ The results show that the perovskite solar cell fabricated from w- $-\mathrm{PbI}_{2}$ precursor film has a higher $R_{\text {rec }}$ 
$(497.9 \Omega)$ than that of $\mathrm{c}-\mathrm{PbI}_{2}(264.1 \Omega)$ and $\mathrm{p}-\mathrm{PbI}_{2}(323.5 \Omega)$, which can be attributed to the increased crystallinity and grain sizes of $\mathrm{w}-\mathrm{PbI}_{2}$-prepared perovskites. Consequently, higher $V_{\mathrm{oc}}$ observed for $\mathrm{w}-\mathrm{PbI}_{2}$-based sample in comparison with that of the others can be unambiguously explained as a result of the lower recombination, resulting from higher recombination resistance. As a result, the cell device fabricated by $\mathrm{w}-\mathrm{PbI}_{2}$ precursor film possesses a low $R_{\mathrm{ct}}$ and a high $R_{\text {rec }}$, which indicates its high charge transfer rate and low carrier recombination rate. We confirmed this by TR-PL measurements. Therefore, the perovskite films prepared with $\mathrm{w}-\mathrm{PbI}_{2}$ film have a high light absorption, increased crystallinity, and high-quality film morphology, and the devices have a low charge transfer resistance and a high recombination resistance, leading to the enhanced photovoltaic performance.

\section{Conclusions}

In summary, we have demonstrated a facile and reproducible approach to obtain high-quality $\mathrm{MAPbI}_{3}$ with excellent photovoltaic performance based on a two-step sequential solution deposition, in which an annealing-free and wet $\mathrm{PbI}_{2}$ film was used as the precursor film. The retarded crystallization and controlled morphology of the annealing-free and wet $\mathrm{PbI}_{2}$ film is favourable to its conversion to $\mathrm{MAPbI}_{3}$, which is due to a direct molecular substitution of DMF molecules intercalated in $\mathrm{PbI}_{2}$ with MAI molecules. Also, the application of the $\mathrm{w}-\mathrm{PbI}_{2}$ film is beneficial to improve the crystallinity, surface morphology and the efficiency of light harvesting of the perovskite films, which further reduces the recombination of photogenerated carriers and increases the life times of charge carriers in the fabricated devices. Compared with the control cell device fabricated by a conventional dry and compact $\mathrm{PbI}_{2}$ films, a significant improvement (nearly 56\%) in the average PCE is obtained from $\mathrm{w}-\mathrm{PbI}_{2}$-based perovskite solar cells. In addition, $\mathrm{PCE}$ of best device fabricated by $\mathrm{w}-\mathrm{PbI}_{2}$ can reach up to $15.49 \%$, with a high stable power output of $15.08 \%$. Therefore, our present work has highlighted an effective strategy to prepare high-quality perovskite films for high-performance perovskite solar cells.

\section{Acknowledgements}

This work is supported by the National Natural Science Foundation of China (No. 11474199) and Research Fund of Jiangsu Key Laboratory for Solar Cell Materials and Technology (No. SKLPSTKF201501). Instrumental Analysis Center of Shanghai Jiao Tong University and National Engineering Research Center for Nanotechnology are sincerely acknowledged for assisting relevant analyses.

\section{Notes and references}

1 A. Kojima, K. Teshima, Y. Shirai and T. Miyasaka, J. Am. Chem. Soc., 2009, 131, 6050-6051.

2 D. B. Mitzi, Prog. Inorg. Chem., 1999, 48, 1-121.
3 K. Tanaka, T. Takahashi, T. Ban, T. Kondo, K. Uchida and N. Miura, Solid State Commun., 2003, 127, 619-623.

4 S. D. Stranks, G. E. Eperon, G. Grancini, C. Menelaou, M. J. Alcocer, T. Leijtens, L. M. Herz, A. Petrozza and H. J. Snaith, Science, 2013, 342, 341-344.

5 J. H. Noh, S. H. Im, J. H. Heo, T. N. Mandal and S. I. Seok, Nano Lett., 2013, 13, 1764-1769.

6 M. R. Filip, G. E. Eperon, H. J. Snaith and F. Giustino, Nat. Commun., 2014, 5, 5757.

7 NREL, Best Research-Cell Efficiencies, http://www.nrel.gov/ ncpv/images/efficiency_chart.jpg, accessed September 1, 2016.

8 J. H. Im, I. H. Jang, N. Pellet, M. Grätzel and N. G. Park, Nat. Nanotechnol., 2014, 9, 927-932.

9 H. S. Kim, C. R. Lee, J. H. Im, K. B. Lee, T. Moehl, A. Marchioro, S. J. Moon, R. Humphry-Baker, J. H. Yum, J. E. Moser, M. Grätzel and N. G. Park, Sci. Rep., 2012, 2, 591-597.

10 W. Z. Li, J. D. Fan, J. W. Li, Y. H. Mai and L. D. Wang, J. Am. Chem. Soc., 2015, 137, 10399-10405.

11 D. Liu and T. L. Kelly, Nat. Photonics, 2013, 8, 133-138.

12 J. W. Jung, S. T. Williams and A. K. Y. Jen, $R S C$ Adv., 2014, 4, 62971-62977.

13 W. S. Yang, J. H. Noh, N. J. Jeon, Y. C. Kim, S. Ryu, J. Seo and S. I. Seok, Science, 2015, 348, 1234-1237.

14 D. Li, P. Liao, X. Shai, W. Huang, S. Liu, H. Li, Y. Shen and M. Wang, RSC Adv., 2016, 6, 89356-89366.

15 J. Burschka, N. Pellet, S. J. Moon, R. Humphry-Baker, P. Gao, M. K. Nazeeruddin and M. Grätzel, Nature, 2013, 499, 316319.

16 D. Bi, S. J. Moon, L. Häggman, G. Boschloo, L. Yang, E. M. J. Johansson, M. K. Nazeeruddin, M. Grätzel and A. Hagfeldt, $R S C A d v ., 2013,3,18762-18766$.

17 W. Zhang, M. Saliba, D. T. Moore, S. K. Pathak, M. T. Hörantner, T. Stergiopoulos, S. D. Stranks, G. E. Eperon, J. A. Alexander-Webber, A. Abate, A. Sadhanala, S. Yao, Y. Chen, R. H. Friend, L. A. Estroff, U. Wiesner and H. J. Snaith, Nat. Commun., 2015, 6, 6142.

18 N. J. Jeon, J. H. Noh, Y. C. Kim, W. S. Yang, S. Ryu and S. I. Seok, Nat. Mater., 2014, 13, 897-903.

19 Z. M. Zhou, Z. W. Wang, Y. Y. Zhou, S. P. Pang, D. Wang, H. X. Xu, Z. H. Liu, N. P. Padture and G. L. Cui, Angew. Chem., Int. Ed., 2015, 54, 9705-9709.

20 Q. Chen, H. Zhou, Z. Hong, S. Luo, H. S. Duan, H. H. Wang, Y. Liu, G. Li and Y. Yang, J. Am. Chem. Soc., 2014, 136, 622625.

21 M. Liu, M. B. Johnston and H. J. Snaith, Nature, 2013, 501, 395-398.

22 L. K. Ono, S. Wang, Y. Kato, S. R. Raga and Y. Qi, Energy Environ. Sci., 2014, 7, 3989-3993.

23 T. Y. Zhang, M. J. Yang, Y. X. Zhao and K. Zhu, Nano Lett., 2015, 15, 3959-3963.

24 Y. Z. Wu, A. Islam, X. D. Yang, C. J. Qin, J. Liu, K. Zhang, W. Q. Peng and L. Y. Han, Energy Environ. Sci., 2014, 7, 2934-2938. 
25 D. H. Cao, C. C. Stoumpos, C. D. Malliakas, M. J. Katz, O. K. Farha, J. T. Hupp and M. G. Kanatzidis, APL Mater., 2014, 2, 091101.

26 B. E. Cohen, S. Gamliel and L. Etgar, APL Mater., 2014, 2, 081502.

27 Y. X. Zhao and K. Zhu, J. Mater. Chem. A, 2015, 3, 9086-9091.

28 L. Zheng, Y. Ma, S. Chu, S. Wang, B. Qu, L. Xiao, Z. Chen, Q. Gong, Z. Wu and X. Hou, Nanoscale, 2014, 6, 8171-8176.

29 P. Docampo, F. Hanusch, S. D. Stranks, M. Döblinger, J. M. Feckl, M. Ehrensperger, N. K. Minar, M. B. Johnston, H. J. Snaith and T. Bein, Adv. Energy Mater., 2014, 4, 1400355.

30 H. A. Harms, N. Tetreault, N. Pellet, M. Bensimon and M. Grätzel, Faraday Discuss., 2014, 176, 251-269.

31 H. Zheng, W. Wang, S. Yang, Y. Liu and J. Sun, RSC Adv., 2016, 6, 1611-1617.

32 W. Fu, J. Yan, Z. Zhang, T. Ye, Y. Liu, J. Wu, J. Yao, C. Z. Li, H. Li and H. Chen, Sol. Energy Mater. Sol. Cells, 2016, 155, 331-340.

33 G. Li, T. Y. Zhang and Y. X. Zhao, J. Mater. Chem. A, 2015, 3, 19674-19678.

34 J. Cao, F. Wang, H. Yu, Y. Zhou, H. Lu, N. Zhao and C.-P. Wong, J. Mater. Chem. A, 2016, 4, 10223-10230.

35 M. Z. Mokhtar, M. Chen, E. Whittaker, B. Hamilton, N. Aristidou, S. Ramadan, A. Gholinia, S. A. Haque, P. O'Brien and B. R. Saunders, Phys. Chem. Chem. Phys, 2017, 19, 7204-7214.

36 C. Y. Sun, Y. P. Guo, B. J. Fang, J. M. Yang, B. Qin, H. N. Duan, Y. J. Chen, H. Li and H. Z. Liu, J. Phys. Chem. C, 2016, 120, 12980-12988.

37 T. H. Liu, Q. Hu, J. Wu, K. Chen, L. C. Zhao, F. Liu, C. Wang, H. Lu, S. Jia, T. Russell, R. Zhu and Q. Gong, Adv. Energy Mater., 2016, 6, 1501890.

38 H. N. Chen, X. L. Zheng, Q. Li, Y. L. Yang, S. Xiao, C. Hu, Y. Bai, T. Zhang, K. S. Wong and S. H. Yang, J. Mater. Chem. A, 2016, 4, 12897-12912.

39 X. W. Chang, W. P. Li, H. N. Chen, L. Q. Zhu, H. C. Liu, H. F. Geng, S. S. Xiang, J. M. Liu, X. L. Zheng, Y. Yang and S. H. Yang, ACS Appl. Mater. Interfaces, 2016, 8, 30184-30192.

40 C. Y. Sun, Y. P. Guo, H. N. Duan, Y. J. Chen, Y. L. Guo, H. Li and H. Z. Liu, Sol. Energy Mater. Sol. Cells, 2015, 143, 360368.

41 M. Yang, Y. Zhou, Y. Zeng, C.-S. Jiang, N. P. Padture and K. Zhu, Adv. Mater., 2015, 27, 6363-6370.
42 H. Zhang, J. Mao, H. He, D. Zhang, H. L. Zhu, F. Xie, K. S. Wong, M. Grätzel and W. C. H. Choy, Adv. Energy Mater., 2015, 5, 1501354.

43 N. Tripathi, M. Yanagida, Y. Shirai, T. Masuda, L. Han and K. Miyano, J. Mater. Chem. A, 2015, 3, 12081-12088.

44 D. W. deQuilettes, S. M. Vorpahl, S. D. Stranks, H. Nagaoka, G. E. Eperon, M. E. Ziffer, H. J. Snaith and D. S. Ginger, Science, 2015, 348, 683-686.

45 H.-S. Ko, J.-W. Lee and N. G. Park, J. Mater. Chem. A, 2015, 3, 8808-8815.

46 C. Roldan-Carmona, P. Gratia, I. Zimmermann, G. Grancini, P. Gao, M. Graetzel and M. K. Nazeeruddin, Energy Environ. Sci., 2015, 8, 3550-3556.

47 V. D'Innocenzo, A. R. S. Kandada, M. De Bastiani, M. Gandini and A. Petrozza, J. Am. Chem. Soc., 2014, 136, 17730-17733.

48 M. Z. Mokhtar, M. Chen, E. Whittaker, B. Hamilton, N. Aristidou, S. Ramadan, A. Gholinia, S. A. Haque, P. O'Brien and B. R. Saunders, Phys. Chem. Chem. Phys., 2017, 19, 7204-7214.

49 G. Xing, N. Mathews, S. Sun, S. S. Lim, Y. M. Lam, M. Gratzel, S. Mhaisalkar and T. C. Sum, Science, 2013, 342, 344-347.

50 J. A. Christians, R. C. M. Fung and P. V. Kamat, J. Am. Chem. Soc., 2014, 136, 758-764.

51 P. P. Boix, G. Larramona, A. Jacob, B. Delatouche, I. MoraSero and J. Bisquert, J. Phys. Chem. C, 2012, 116, 1579-1587.

52 P. P. Boix, Y. H. Lee, F. Fabregat-Santiago, S. H. Im, I. MoraSero, J. Bisquert and S. I. Seok, ACS Nano, 2012, 6, 873-880.

53 H. S. Kim, I. Mora-Sero, V. Gonzalez-Pedro, F. FabregatSantiago, E. J. Juarez-Perez, N. G. Park and J. Bisquert, Nat. Commun., 2013, 4, 2242.

54 X. Cao, C. Li, Y. Li, F. Fang, X. Cui, Y. Yao and J. Wei, Nanoscale, 2016, 8, 19804-19810.

55 E. J. Juarez-Perez, M. Wußler, F. Fabregat-Santiago, K. LakusWollny, E. Mankel, T. Mayer, W. Jaegermann and I. MoraSero, J. Phys. Chem. Lett., 2014, 5, 680-685.

56 J. Zhang, E. J. Juarez-Perez, I. Mora-Sero, B. Viana and T. Pauporte, J. Mater. Chem. A, 2015, 3, 4909-4915.

57 V. Gonzalez-Pedro, E. J. Juarez-Perez, W. S. Arsyad, E. M. Barea, F. Fabregat-Santiago, I. Mora-Sero and J. Bisquert, Nano Lett., 2014, 14, 888-893.

58 A. Dualeh, T. Moehl, N. Tetreault, J. Teuscher, P. Gao, M. K. Nazeeruddin and M. Grätzel, ACS Nano, 2014, 8, 362-373. 